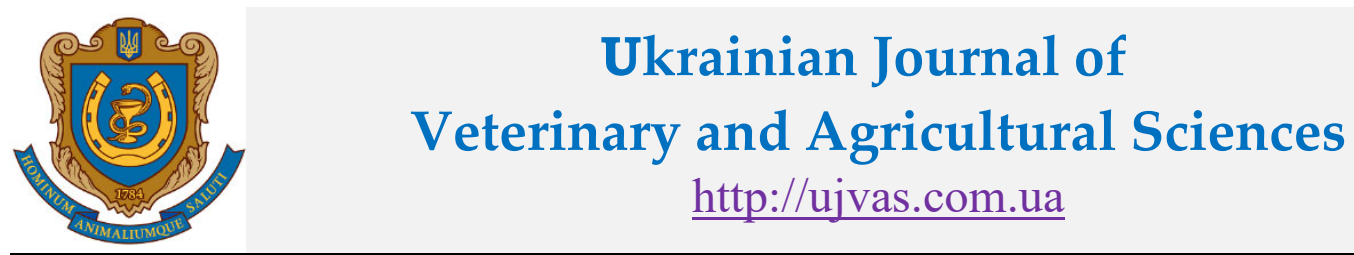

Stepan Gzhytskyi National University of Veterinary Medicine and Biotechnologies Lviv

\begin{tabular}{l|l|l} 
original article & UDC $623.4: 633.854 .78$ & doi: $\mathbf{1 0 . 3 2 7 1 8 / u j v a s 4 - 2 . 0 2}$
\end{tabular}

\title{
Design of antigen synthesis and identification of its artificial antigen for zearalenone
}

\author{
Yanan Wang ${ }^{1,2}$, Hanna Fotina ${ }^{1}$, Alexsey Fotin ${ }^{1}$ \\ ${ }^{1}$ Faculty of Veterinary Medicine, Sumy National Agrarian University, Sumy, 40021, Ukraine \\ ${ }^{2}$ College of Animal Science and Veterinary Medicine, Henan Institute of Science and Technology, Xinxiang, 453003, China
}

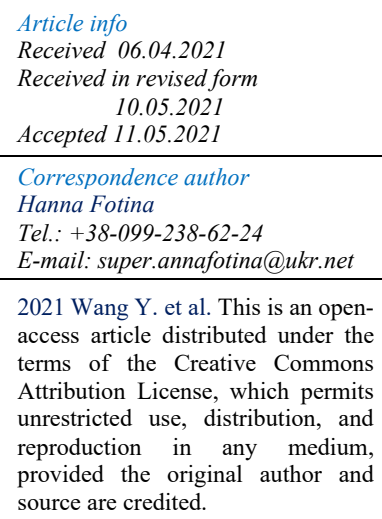

\begin{abstract}
Background: study aimed to modify the ZEN molecule and conjugate the carrier protein to prepare a complete antigen. To lay the foundation for the preparation of ZEN monoclonal antibodies. Methods: The carbonyl group at the 7 position of ZEN molecule was modified by deuteration reaction. The immunogen and antigen were synthesized by EDC method and mixed acid anhydride method, and the complete antigen was identified by UV, IR and electrophoresis. Antisera were obtained after immunization of animals, and an antiserum was designed by ELISA. Results: The immunogens were identified by UV, IR and electrophoresis, ZEN-BSA was successfully synthesized. The ratio of ZEN-BAS to ZEN was calculated to be $1: 13$. When the antibody serum was detected, the titer of the antibody reached 1:(6.4×103). Conclusion: This study demonstrated that the OAE method is preferable in preparing the ZEN. These findings lay the material and technical foundation for the preparation of anti-ZEN monoclonal antibody
\end{abstract}

Key words: ZEN, Artificial antigen, Polyclonal antibody, Performance Identification.

\section{(cc) EY}

Contents

1. Introduction .....

2. Materials an

3. Results and discussion ....... 9

4. Conclusions .................. 11

References .................... 11

\section{Citation:}

Wang, Y., Fotina, H., \& Fotin, A. (2021). Design of antigen synthesis and identification of its artificial antigen for zearalenone. Ukrainian Journal of Veterinary and Agricultural Sciences, 4(2), 7-12.

\section{Introduction}

Zearalenone (ZEN) was produced due to the growth of Fusarium graminearum caused by improper storage or improper temperature of corn soybean meal and other feeds (Niermans et al., 2019). Most of Zen grow in plants and widely exists in food, which reduces the nutritional value of food and remains in human and animals (Rogowska et al., 2019), giving a great threat to human food safety. There are many derivatives of ZEN, including $\alpha$-Zearalenol $(\alpha-Z O L)$, $\beta$-Zearalenol ( $\beta$-ZOL), $\alpha$-Zeranol ( $\alpha$-ZER), $\beta$-zearalenol $(\beta$ ZER) and Zearalanone (ZAN). The relationship between these five derivatives is as follows: Fusarium sp. grows in grain and produces toxic metabolite ZEN, which mainly metabolizes two products, $\alpha$-ZER and $\beta$-ZER (Faisal et al., 2018 ), among which the main product is $\alpha$-ZER, accounting for $99 \%$ of the metabolites. After they enter the animal body, $\alpha-Z O L$ and $\beta-Z O L$ are formed by reduction reaction, and finally ZAN is formed. ZEN has the effect of estrogen
(Zheng et al., 2019), which can cause reproductive and immune diseases such as abnormal breeding function, cytotoxicity (Fig. 1).

Studies have shown that ZEN and its metabolites have estrogen activity in pigs, cattle and other animals (Zhang et al., 2018). The clinical treatment of diseases caused by a variety of mycotoxins will cause huge medical costs (Jia et al., 2014; Liu et al., 2014). The EU stipulates that the MRL of ZEN in cereals and grain products is $2 \mathrm{mg} / \mathrm{kg}$; the MRL of ZEN in corn by-products is $3 \mathrm{mg} / \mathrm{kg}$; the MRL of ZEN in compound feeds for piglets and young sows are $0.1 \mathrm{mg} / \mathrm{kg}$ (EC, 2007). The current ZEN MRL standard of food and agricultural products in China is "GB 2761-2017 Food Mycotoxin Limit", which strictly stipulates that the MRL of ZEN in wheat, wheat flour, corn, and cornflour is $0.06 \mathrm{mg} / \mathrm{kg}$ (CHINA, 2017). Italy stipulates that the MRL of ZEN in grains and cereal products is $0.1 \mathrm{mg} / \mathrm{kg}$ (Bertuzzi et al., 2014); Australia stipulates that the MRL of ZEN in grains is $0.05 \mathrm{mg} / \mathrm{kg}$ (Tan et al., 2011) However, $\alpha$-ZOL has the 
strongest toxicity, which is 10-20 times higher than ZEN (Yang et al., 2019; Rai et al., 2020). Therefore, single ZEN detection cannot meet the needs of food and feed industry, this has prompted immense research on detecting the total amount of ZEN and its homologues.

According to the physical and chemical properties of ZEN, the detection method of the material can be determined mainly with thin layer chromatography (TLC), gas chromatography (GC), gas chromatography - mass spectrometry (GC-MS), etc. (Kresse et al., 2019). However, these methods cannot meet the requirements of mycotoxin determination due to their low yield, long cycle, requiring professional operation and tedious sample pretreatment (Selvaraj et al., 2015). Immunological detection technology has the advantages of simplicity, high efficiency and broad spectrum, and has gradually become one of the important methods to detect biological toxins (Xu et al., 2018; Chen et al., 2019). In this study, the method of oximation (Dong et al., 2018) was used to react with carboxymethoxylamine hemihydrochloride to modify the ketone group on the molecular formula and synthesize hapten. The artificial antigen was synthesized by EDC method and mixed anhydride method by coupling with BSA and ova. In antibody detection, horse serum was used as blocking solution for detection (Sun et al. 2014). The detection results of indirect ELISA showed that the titer of antiserum was high. This study also provides the basis for the preparation and identification of monoclonal antibodies.<smiles>CO[C@H](C)CCCCCC(=O)CCC=Cc1cc(O)cc(O)c1C(=O)O</smiles>

Fig. 1. The chemical structure of zearalenone

\section{Materials and methods}

2.1 Chemicals and Reagents. The standard of ZEN, $\alpha$ ZER, $\beta$-ZER, $\alpha$-ZOL, $\beta$-ZOL, ZAN and polyethylene glycol (PEG-1500) purchased from Sigma. Bovine serum albumin (BSA), chicken ovalbumin (OVA) were provided by Pierce. Goat Anti-Mouse IgG-horseradish peroxidase (IgG-HRP), phenol red was provided by Solarbio. 3,3,5,5Tetramethylbenzidine (TMB), 1,4 dioxane, Tributylamine isobutyl chlorocarbonate, potassium bromide, RPMI-1640 medium purchased from Gibco., colchicine was provided by Shanghai Yansheng Biochemical Co., Ltd .in addition, 6well cell and 24-well cell culture plates, cell culture bottle, 96-well microtiter plates 96 were purchased from Corning company. Hypoxantin Aminopterin and Thymidin (HAT), Hypoxantin and Thymidin (HT) were all made in-house in our laboratory.

ZEN standard solution, dilute $60 \%$ methanol with PBS to a dissolved concentration of $1 \mathrm{mg} / \mathrm{mL}$, then dilute it to $8 \mathrm{ng} / \mathrm{mL}$, $4 \mathrm{ng} / \mathrm{mL}, 2 \mathrm{ng} / \mathrm{mL}, 1 \mathrm{ng} / \mathrm{mL}, 0.5 \mathrm{ng} / \mathrm{mL}, 0.25 \mathrm{ng} / \mathrm{mL}$, $0.125 \mathrm{ng} / \mathrm{mL}, 0.062 \mathrm{ng} / \mathrm{mL}, 0.031 \mathrm{ng} / \mathrm{mL}, 0 \mathrm{ng} / \mathrm{mL}$.

2.2 Equipment and Instruments. Exceed DZG-303A ultrapure water polishing system was purchased from Chengdu Kangning Special Experiment Pure Water Equipment Factory (Chengdu, China), a 303A-1 electric heating constant temperature incubator was purchased from Beijing Zhongxing Weiye Instrument Co., Ltd. (Beijing, China) NEVAP nitrogen blower were purchased from (Organomation, USA) The infrared (IR) spectra were obtained using a Bruker Tensor 27 spectrometer (Bruker, Germany), while the ultraviolet (UV)-visible spectra were obtained with a DU-800 UV-visible spectrophotometer (Beckman-Coulter, Fullerton, CA,). JY300C electrophoresis apparatus and gel imaging system were purchased from Beijing Junyi Dongfang electrophoresis equipment Co., Ltd. (Beijing, China). In addition, a spectrophotometric microtiter reader (MULTISKAN MK3, Thermo Co., Shanghai, China) was used to measure the absorbance.

2.3 Experimental animals. 6-8 weeks old female $\mathrm{Balb} / \mathrm{c}$ mice and feed provided by the Experimental Animal Center of Medical College of Zhengzhou University (Zhengzhou, China), and were given tap water and $a$ diet ad libitum.

2.4 Synthesis of Immunogen. According to the molecular structure and active site of ZEN, the immunogen and coating antigen were synthesized via oxime active ester (OAE) (Cha et al., 2012), synthetic semi-antigen ZEN-CMO (Fig. 2). The carboxyl group of ZENO and the amino group of BSA were coupled with a monoamide bond under the action of EDC to synthesize artificial immunogen ZENBSA. ZENO was dissolved in $2 \mathrm{~mL}$ dioxane, after which 3 $\mathrm{mg}$ NHS and $7 \mathrm{mg}$ EDC were added, stirred at $4{ }^{\circ} \mathrm{C}$ for $4 \mathrm{~h}$ to prepare the hapten activation solution. Then added $1 \mathrm{ml}$ of 1,4 dioxane and $45 \mathrm{ml}$ of tri-n-butylamine were added respectively, and the reaction time was $20 \mathrm{~min}$ in ice bath, $60 \mu 1$ isobutyl chloroformate and the reaction time was $2 \mathrm{~h}$ in ice bath conditions. The hapten activation solution, $1 \mathrm{~mL}$ cBSA activation solution was added at a concentration of $20 \mathrm{mg} / \mathrm{mL}$ dropwise. The reaction solution was stirred at $4{ }^{\circ} \mathrm{C}$ for $4 \mathrm{~h}$, then dialyzed with PBS at $4{ }^{\circ} \mathrm{C}$ for three days. The dialysate was changed once a day and stored at $-20{ }^{\circ} \mathrm{C}$ for subsequent applications. The synthetic route of $\mathrm{ZEN}$ BSA (OAE) is shown in Figure 3. The coating antigen ZENOVA (OAE) was prepared via the same method.<smiles>CC(CCCCCC(=O)OCC(=O)O)OC(=O)c1c(O)cc(O)cc1/C=C/CCCC(=O)CCCC(C)OC(O)c1c(O)cc(O)cc1/C=C/CCCC(=O)OCO</smiles>

Fig. 2. ZEN-CMO synthesis route 


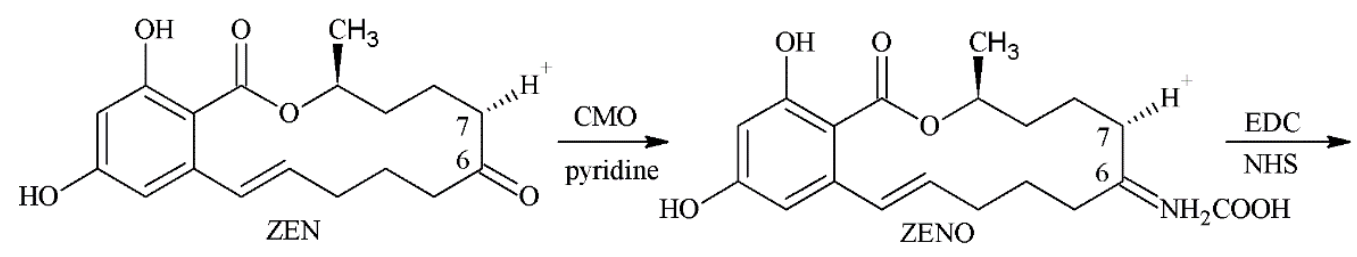

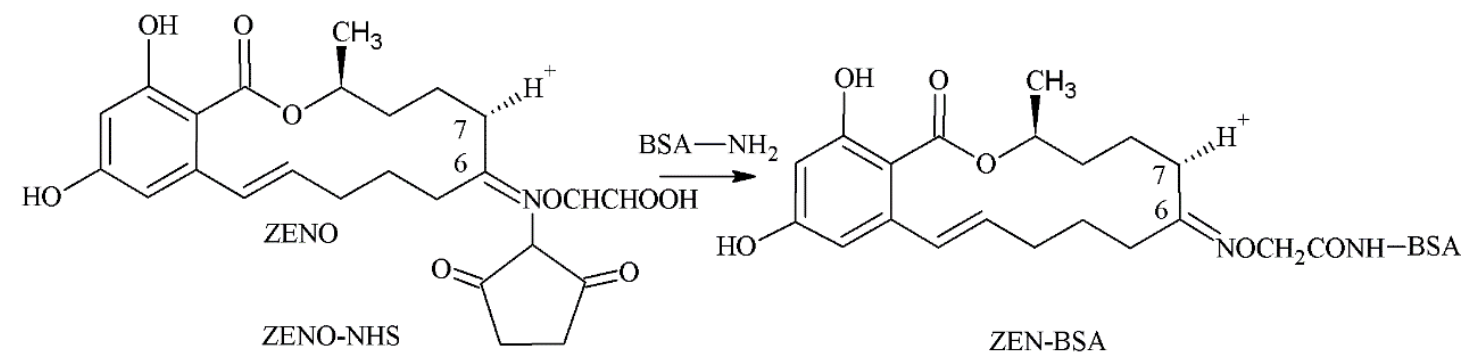

Fig. 3. Synthesis route of the ZEN-BSA by the OAE method

2.5 Identifying the Artificial Immunogen. UV identification: The PBS buffer was used as a blank control and the baseline was calibrated. Configure the concentration of BSA and OVA to $1 \mathrm{mg} / \mathrm{ml}$. The antigen ZEN-BSA and ZEN-OVA were diluted to a protein concentration of $1 \mathrm{mg} / \mathrm{ml}$. Dilute the standard to $20 \mu \mathrm{g} / \mathrm{ml}$ for ultraviolet scanning (Jiang et al., 2014). IR identification: During infrared scans, powder samples are needed. First, the artificial antigen was freezedried, and the dried potassium bromide was prepared. Then, the dried trace antigen and potassium bromide were mixed at the ratio of $1: 100$, and then ground. Finally, the tablet was pressed and measured on the machine (Wang et al., 2012). SDS-PAGE identification: Here, $5 \%$ concentration gel and $12 \%$ separation gel were selected for electrophoresis analysis. The test voltage for the concentrated gel was $100 \mathrm{~V}$, while that for the separation gel was $60 \mathrm{~V}$. Also, $10 \mu \mathrm{L} /$ hole sample volume and $10 \mu \mathrm{g} /$ hole protein content were used (Pedersen et al., 2006).

2.6 Preparation of ZEN pAb. Referring to the method of Kim S. H. et al. (Kim et al., 2011) and improve it. Five female BALB/c mice aged 6-8 weeks were immunized with ZEN-BSA and injected subcutaneously with $50 \mu \mathrm{g}$ /mouse. The mice were immunized once every three weeks for five times. The antibody titer was determined by indirect ELISA. On 96 well plate, the concentration of the coated plate was determined to be $2 \mu \mathrm{g} / \mathrm{ml}$ by square matrix titration. The artificial antigen ZEN-OVA was diluted with CBS at $4{ }^{\circ} \mathrm{C}$ overnight, blocked with $5 \%$ horse serum and $5 \%$ pig serum blocking solution respectively, and incubated at $37{ }^{\circ} \mathrm{C}$ for $1 \mathrm{~h}$ as control, and was coated with blocking solution at $50 \mu \mathrm{L}$. The second antibody and Goat anti mouse IgG (diluted to the working concentration with blocking solution) were added and incubated at $37{ }^{\circ} \mathrm{C}$ for $25 \mathrm{~min}$. the chromogenic solution was added for $10 \mathrm{~min}$. finally, the reaction was terminated. OD450 value was determined by enzyme reader. The above steps were washed three times with $0.05 \%$ Tween-20 in PBS every time interval of 3 min.

\section{Results and discussion}

\section{Results}

UV Identification. In the range of UV $220-400 \mathrm{~nm}$, BSA had characteristic absorption peaks for UV at $278 \mathrm{~nm}$, and ZEN had characteristic absorption peaks for UV at $236 \mathrm{~nm}, 274 \mathrm{~nm}$, and $316 \mathrm{~nm}$, respectively (Fig. 4). The artificial immunogen ZEN-BSA had characteristic absorption peaks for $U V$ at $276 \mathrm{~nm}$. Therefore, the absorption peak has shifted, which proves that the artificial antigen coupling is successful.

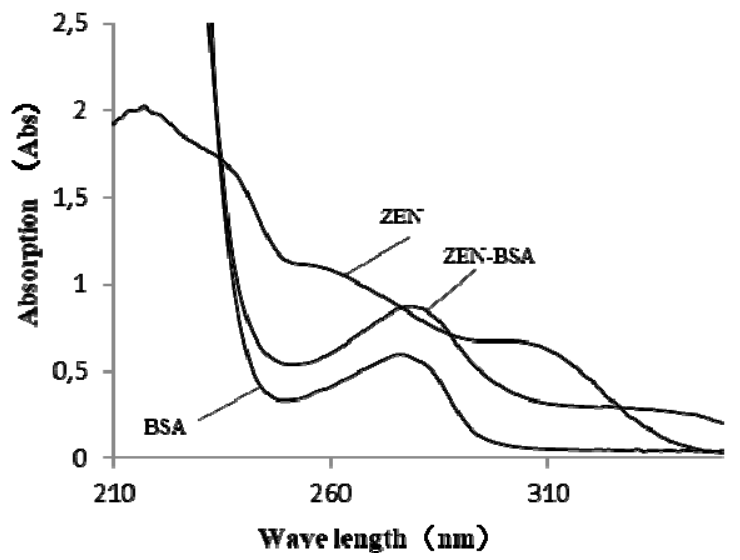

Fig. 4. UV spectra of ZEN-BSA synthesized

IR Identification. The results of the identification are shown in Figure 5 Comparing the IR of the artificial immunogen ZEN-BSA synthesized with BSA, we revealed similar IR absorption in the regions $2500-3000 \mathrm{~cm}-1$ and 1000 $1500 \mathrm{~cm}-1$, which were the characteristic peaks produced by the amine group and amide group in BSA (Fig. 5). This finding revealed that the method successfully synthesized the artificial immunogen ZEN-BSA.

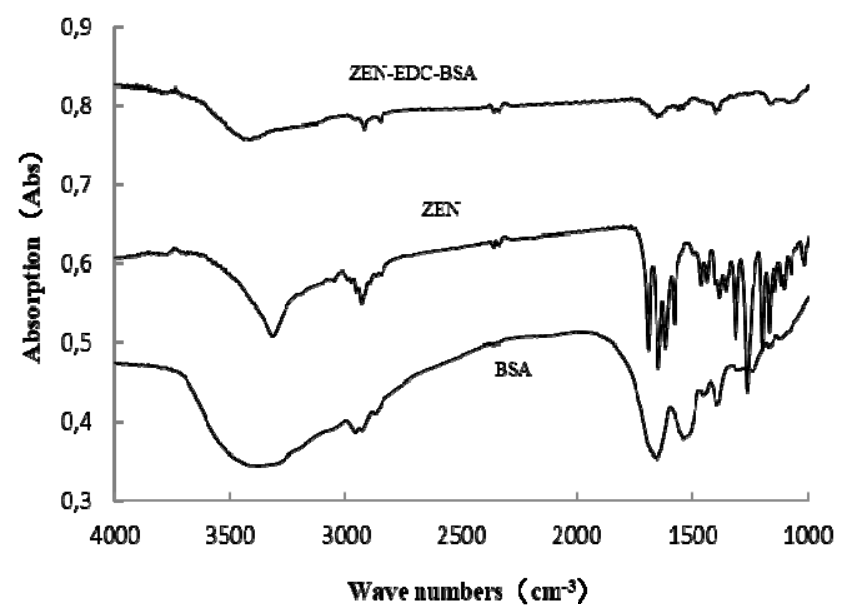

Fig. 5. IR spectra of ZEN-BSA synthesized 
SDS-PAGE Identification. As shown in Figure 6, under the same conditions, the BSA is fast than the migration speed of ZEN-BSA, indicating that the molecular mass of Zen-BSA is large, indicating that the artificial antigen synthesis is successful. The gel imaging system was detected that the ZEN-BSA molecular weight was 70569.3, and the molecular weight of the BSA was 66430. Calculated, ZENBSA and ZEN coupling ratio of $1: 13$.

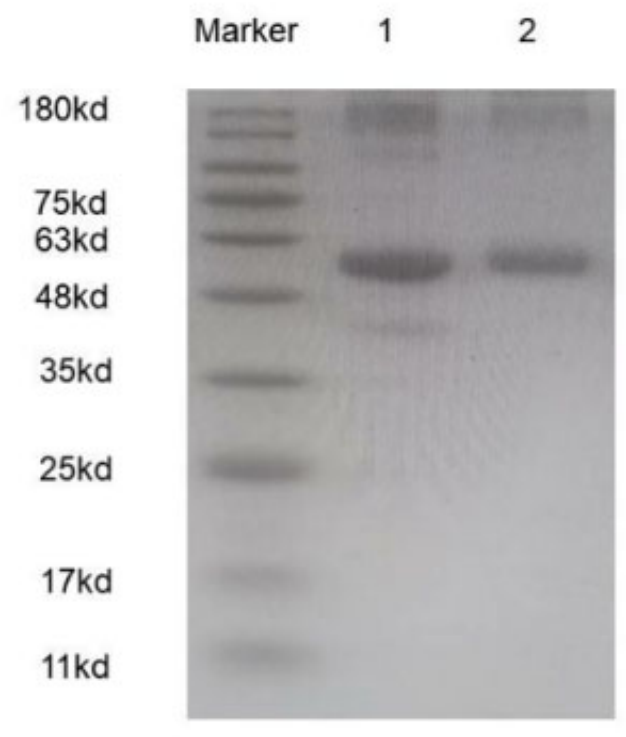

Fig. 6. SDS-PAGE identification of artificial antigen ZENBSA. 1 Marker; 2 BSA; 3 ZEN-BSA

3.4 ZEN pAb Characteristic Analysis. The titers of antibody in serum of mice were shown in Table 1 and table 2, and detected by ELISA, the titers of 5 mice were all $1:(6.4 \times 103)$, the highest titer of horse serum blocking solution was $1:(1.024 \times 105)$, and the highest titer of pig serum blocking solution was $1:(1.28 \times 104)$. The negative and blank detection values of pig serum blocking solution were higher than those of horse serum blocking solution, and the background value of pig serum blocking solution was higher. which is visible, horse Serum blocking liquid is better, so the experiment is selected from the selection of horse serum as a block. Horse serum was used as blocking fluid.

\section{Discussion}

Design of ZEN immunogen synthesis method. ZEN is a small molecule substance with reactivity, but it does not have immunogenicity. There is no active group that can be directly coupled with carrier protein. Therefore, it is necessary to modify the Zen molecule through the coupling vector protein, so that it induces the body to produce immunization response reaction, it is necessary to modify Zen molecule to induce immune response by coupling carrier protein (Cao et al., 2011). In this study, the ZEN molecule was modified to synthesize a hapten by the oximation method, and an artificial antigen was synthesized after coupling with the protein. In antigen synthesis, the reaction ratio between $\mathrm{ZEN}$ and EDC is ZEN : EDC $=1: 2-3$, and NHS should be less than or equal to the amount of EDC. NHS acts as a catalyst to activate and protect the carboxyl group. When catalyzing esters, it must be alkaline Under the conditions. Therefore, the EDC cannot be dissolved in DDW, and it is necessary to react under the alkaline system, and the $\mathrm{pH}$ should be controlled between 8.0-8.4, Dicyclohexylurea precipitation will be formed when excess NHS reacts with oxime and carrier. In this experiment, in the antigen synthesis, an EDC method for immune antigen is coupled to the carrier protein BSA, and the antigenic mixed acid anhydride method is detected to be coupled to the carrier protein OVA, thereby avoiding the production of bridge resistance. The key of immunoassay technology is to synthesize the artificial antigen with good immunogenicity, so as to obtain the antibody of zearalenone with high titer and strong specificity. Therefore, the preparation of artificial antigen is one of the most critical steps in the preparation of monoclonal antibody.

Table 1

Determination of immunogen indirect ELISA by horse serum blocking solution (OD450)

\begin{tabular}{|c|c|c|c|c|c|c|c|c|c|c|c|c|}
\hline \multirow{2}{*}{ Number } & \multicolumn{10}{|c|}{ Dilute multiple } & \multirow{2}{*}{ negative } & \multirow{2}{*}{ blank } \\
\hline & $1: 200$ & $1: 400$ & $1: 800$ & $1: 1600$ & $1: 3200$ & $1: 6400$ & $1: 12800$ & $1: 25600$ & $1: 51200$ & $1: 102400$ & & \\
\hline 1 & 2.017 & 1.345 & 0.862 & 0.500 & 0.319 & 0.184 & 0.156 & 0.141 & 0.085 & 0.079 & 0.071 & 0.088 \\
\hline 2 & 1.746 & 0.875 & 0.480 & 0.325 & 0.177 & 0.147 & 0.115 & 0.090 & 0.071 & 0.065 & 0.067 & 0.065 \\
\hline 3 & 1.963 & 1.261 & 0.718 & 0.474 & 0.305 & 0.171 & 0.113 & 0.103 & 0.073 & 0.063 & 0.068 & 0.063 \\
\hline 4 & 3.764 & 2.927 & 2.347 & 1.905 & 1.492 & 1.149 & 0.713 & 0.448 & 0.386 & 0.367 & 0.065 & 0.060 \\
\hline 5 & 2.819 & 1.912 & 1.346 & 0.959 & 0.645 & 0.417 & 0.275 & 0.202 & 0.193 & 0.110 & 0.057 & 0.058 \\
\hline
\end{tabular}

Table 2

Determination of immunogen indirect ELISA results in pig serum blocking solution (OD450)

\begin{tabular}{|c|c|c|c|c|c|c|c|c|c|c|c|c|}
\hline \multirow{2}{*}{ Number } & \multicolumn{10}{|c|}{ Dilute multiple } & \multirow[b]{2}{*}{ negative } & \multirow{2}{*}{ blank } \\
\hline & $1: 200$ & $1: 400$ & $1: 800$ & $1: 1600$ & $1: 3200$ & $1: 6400$ & $1: 12800$ & $1: 25600$ & $1: 51200$ & $1: 102400$ & & \\
\hline 1 & 1.329 & 0.798 & 0.684 & 0.503 & 0.388 & 0.213 & 0.144 & 0.099 & 0.072 & 0.072 & 0.099 & 0.082 \\
\hline 2 & 0.902 & 0.572 & 0.281 & 0.157 & 0.134 & 0.121 & 0.111 & 0.087 & 0.082 & 0.068 & 0.088 & 0.084 \\
\hline 3 & 1.308 & 0.882 & 0.724 & 0.573 & 0.400 & 0.303 & 0.211 & 0.089 & 0.078 & 0.072 & 0.094 & 0.083 \\
\hline 4 & 1.481 & 1.129 & 0.892 & 0.761 & 0.524 & 0.304 & 0.177 & 0.138 & 0.101 & 0.094 & 0.095 & 0.089 \\
\hline 5 & 1.374 & 0.848 & 0.619 & 0.443 & 0.273 & 0.209 & 0.179 & 0.119 & 0.104 & 0.071 & 0.098 & 0.092 \\
\hline
\end{tabular}


Non-specific reactions about enclosed liquid horse serum. When different animals are used as sealing fluid, because the background value is different, the sealing fluid with lower background value should be selected, so that the influence of antiserum is small, the titer is high, and the gradient is obvious. When selecting serum, it is necessary to select the animal which is far from other animals to avoid the error of test results. Meanwhile, if the blocking serum contains the target protein and has the same source as the primary antibody, the blocking serum with the same source as the secondary antibody can be used. In addition, during animal feeding, pigs mainly eat feed and grain. A small amount of mycotoxins contained in feed or grain can directly enter pigs, which may cause the problem of animal homology. Horses mainly eat grass, which directly eliminates the problem of homology. Antibodies recognize antigenic determinants and then bind to them. Pig serum and horse serum are mainly blocked by protein, and the adsorption capacity of protein is very strong. When horse serum is used as the blocking solution, the background value is lower, and the non-specific reaction is weak. It can better block the remaining antigen sites on the enzyme plate and combine with the antigen determinants on the surface, so as to achieve better blocking effect (Gaimei et al., 2013).

In regard to antibody titer. According to the current research progress, the indirect ELISA method was used and optimized (Sompunga et al., 2019). Compared with pig serum, horse serum has higher titer and better stability. The highest titer was 1:1.024×105 (Yaning, 2017). The kit prepared by the indirect ELISA method prepared by corn bibarone is applied to production, and the detection effect will be improved. Support for the development of ZEN kits, promoting the development of enzyme-linked immunization techniques to some extent, is of great significance for human food safety issues, and has certain innovation, providing technical support for farming industry.

\section{Conclusions}

In the immunological analysis method, the preparation of the antigen is a key part of the antibody and the establishment of an immunological test method. Through the above identification results showed that the ZEN-BSA artificial antigen and ZEN-OVA coating antigen were successfully synthesized by antigen, and horse serum has higher titer and better stability. Thus, the results of this study are successfully established immunological testing methods, which laid a foundation for the preparation of monoclonal antibody.

Ethical approval and animal rights: All experiments were conducted in accordance with the "Guidelines for the Care and Use of Laboratory Animals" of the National Institutes of Health and were approved by the Animal Ethics Committee of Henan Institute of Science and Technology. The approval number is Issue No. 2020HIST047.

Author Contributions: Conceptualization, H. Fotina and Y. Wang; software, Y. Wang; formal analysis, data curation, Y. Wang; writing-original draft preparation, Y. Wang; writing-review and editing, H. Fotina; supervision, H. Fotina. All authors have read and agreed to the published version of the manuscript.
Acknowledgments: The authors would like to thank Open Laboratory of Key Disciplines for Animal Viral Diseases and Drug Residues of Henan Provincial Higher Education of support.

Conflicts of Interest: The authors declare no conflict of interest.

\section{References}

Bertuzzi, T., Camardo Leggieri, M., Battilani, P., \& Pietri, A. (2014). Co-occurrence of type A and B trichothecenes and zearalenone in wheat grown in northern Italy over the years 2009-2011. Food Addit Contam Part B Surveill, 7, 273-281. doi: 10.1080/19393210.2014.926397.

Cao, H., Ji, F., Wang, X. Y., \& Shi, J. R. (2011). [Synthesis and identification of the hapten and complete antigens for Zearalenone] Xi Bao Yu Fen Zi Mian Yi Xue Za Zhi, 27(9), 975-978. URL: https://pubmed.ncbi.nlm.nih.gov/21906470.

Cha, S. H., Kim, S. H., Bischoff, K., Kim, H. J., Son, S. W., \& Kang, H. G. (2012) Production of a highly group-specific monoclonal antibody against zearalenone and its application in an enzyme-linked immunosorbent assay. $J$ Vet Sci., 13(2), 119125 doi: 10.4142 jvs.2012.13.2.119.

Chen, X.-Q., Zhao, W., Xie, S.-W., Xie, J.-J., Zhang, Z.-H., Tian, L.-X., Liu, Y.-J., \& Niu, J. (2019). Effects of dietary hydrolyzed yeast (Rhodotorula mucilaginosa) on growth performance, immune response, antioxidant capacity and histomorphology of juvenile Nile tilapia (Oreochromis niloticus). Fish Shellfish Immunol, 90, 30-39. doi: 10.1016/j.fsi.2019.03.068.

CHINA (2017). National Food Safety Standard Limit of mycotoxins in food vol GB $2761-2017$.

Dong, G., Pan, Y., Wang, Y., Ahmed, S., Liu, Z., Peng, D., \& Yuan, Z. (2018). Preparation of a broad-spectrum anti-zearalenone and its primary analogues antibody and its application in an indirect competitive enzyme-linked immunosorbent assay. Food Chem, 247, 8-15 doi: 10.1016/j.foodchem.2017.12.016.

EC (2007). Setting maximum levels for certain contaminants in foodstuffs as regards Fusarium toxins in maize and maize products (Text with EEA relevance) vol No.1126/2007.

Faisal, Z., Lemli, B., Szerencsés, D. et al. (2018) Interactions of zearalenone and its reduced metabolites $\alpha$-zearalenol and $\beta$ zearalenol with serum albumins: species differences, binding sites, and thermodynamics. Mycotoxin Res, 34, 269-278. doi: 10.1007/s12550-018-0321-6.

Gaimei, D. U., Liu, M., Gan, Y., Wei, Y., \& Yuzi, W. U. (2013). Study on Screening of Optimal Blocking Buffer and Sample Diluent for ELISA. Agricultural Science and Technology, 14, 816-819, 837 doi: 10.16175/j.cnki.1009-4229.2013.06.027.

Jia, Z., Liu, M., Qu, Z., Zhang, Y., Yin, S., \& Shan, A. (2014). Toxic effects of zearalenone on oxidative stress, inflammatory cytokines, biochemical and pathological changes induced by this toxin in the kidney of pregnant rats. Environ Toxicol Pharmacol, 37(2), 580-591. doi: 10.1016/j.etap.2014.01.010.

Jiang, J. Q., Zhang, H. T., Zhang, H. H., Wang, Z. L., Yang, X. F., \& Fan, G. Y. (2014). Development of an enzyme-linked immunosorbent assay for detection of clopidol residues in chicken tissues. J Sci Food Agric, 94(11), 2295-2300. doi:10.1002/jsfa.6557.

Kim, S. H., Cha, S. H., Karyn, B., Park, S. W., \& Kang, H. G. (2011). Production of Group Specific Monoclonal Antibody to Aflatoxins and its Application to Enzyme-linked Immunosorbent Assay. Toxicological Research, 27(2), 125-131 doi: 10.5487/TR.2011.27.2.125.

Kresse, M., Drinda H., Romanotto, A., \& Speer, K. (2019). Simultaneous determination of pesticides, mycotoxins, and metabolites as well as other contaminants in cereals by LC-LCMS/MS. J Chromatogr B Analyt Technol Biomed Life Sci, 1117, 86-102. doi: 10.1016/j.jchromb.2019.04.013. 
Liu, M., Gao, R., Meng, Q., Zhang, Y., Bi, C., Shan, A. (2014). Toxic effects of maternal zearalenone exposure on intestinal oxidative stress, barrier function, immunological and morphological changes in rats. PloS one, 9, e106412 doi: 10.1371/journal.pone.0106412.

Niermans, K., Woyzichovski, J., Kröncke, N., Benning, R., \& Maul, R. (2019). Feeding study for the mycotoxin zearalenone in yellow mealworm (Tenebrio molitor) larvae-investigation of biological impact and metabolic conversion. Mycotoxin Res 35, 231-242. doi: 10.1007/s12550-019-00346-y.

Pedersen, M. K., Sorensen, N. S., Heegaard, P. M., Beyer, N. H., \& Bruun, L. (2006). Effect of different hapten-carrier conjugation ratios and molecular orientations on antibody affinity against a peptide antigen. J Immunol Methods, 311(1-2), 198-206. doi: 10.1016/j.jim.2006.02.008.

Rai, A., Das, M., \& Tripathi, A. (2020). Occurrence and toxicity of a fusarium mycotoxin, zearalenone. Crit Rev Food Sci Nutr, 60(16), 2710-2729. doi: 10.1080/10408398.2019.1655388.

Rogowska, A., Pomastowski, P., Sagandykova, G., \& Buszewski, B. (2019). Zearalenone and its metabolites: Effect on human health, metabolism and neutralisation methods. Toxicon, 162, 46-56. doi: 10.1016/j.toxicon.2019.03.004.

Selvaraj, J. N., Wang, Y., Zhou, L., Zhao, Y., Xing, F., Dai, X., \& Liu, Y. (2015). Recent mycotoxin survey data and advanced mycotoxin detection techniques reported from China: a review. Food Addit Contam Part A Chem Anal Control Expo Risk Assess, 32(4), 440-452. doi: 10.1080/19440049.2015.1010185.

Sompunga, P., Pruksametanan, N., Rangnoi, K., Choowongkomon, K., \& Yamabhai, M. (2019). Generation of human and rabbit recombinant antibodies for the detection of Zearalenone by phage display antibody technology. Talanta, 201, 397-405. doi: 10.1016/j.talanta.2019.04.034.
Sun, Y., Hu, X., et al. (2014). Development of an immunochromatographic strip test for the rapid detection of zearalenone in corn. J Agric Food Chem, 62, 11116-11121. doi: 10.1021/jf503092j.

Tan, D. C., Flematti, G. R., Ghisalberti, E. L., Sivasithamparam, K., Chakraborty, S., Obanor, F., \& Barbetti, M. J. (2011). Mycotoxins produced by Fusarium species associated with annual legume pastures and 'sheep feed refusal disorders' in Western Australia. Mycotoxin Res, 27(2), 123-135. doi: 10.1007/s12550-010-0085-0.

Wang, Y., He, C. H., Zheng, H., \& Zhang, H. B. (2012). Characterization and comparison of Fumonisin $\mathrm{B}(1)$-protein conjugates by six methods. Int J Mol Sci, 13(1), 84-96. doi: 10.3390/ijms13010084.

Xu, Y., Yang, H., et al. (2018). A peptide/maltose-binding protein fusion protein used to replace the traditional antigen for immunological detection of deoxynivalenol in food and feed. Food Chem, 268, 242-248. doi: 10.1016/j.foodchem.2018.06.096.

Yang, C.K., Cheng Y., et al. (2019). Prevalence of mycotoxins in feed and feed ingredients between 2015 and 2017 in Taiwan. Environ Sci Pollut Res Int, 26(23), 23798-23806. doi: 10.1007/s11356-019-05659-0.

Yaning, S. (2017). Study on Immunological Rapid Determination of Zearalenone Gansu Agricultural University, China.

Zhang, G. L., Feng, Y. L., Song, J. L., Zhou, X. S. (2018). Zearalenone: A Mycotoxin With Different Toxic Effect in Domestic and Laboratory Animals' Granulosa Cells. Front Genet. doi: 10.3389/fgene.2018.00667.

Zheng, W. L., Feng, N., et al. (2019). Effects of zearalenone and its derivatives on the synthesis and secretion of mammalian sex steroid hormones: A review. Food Chem Toxicol, 126, 262276. doi: 10.1016/j.fct.2019.02.031. 